\title{
Cocinando la revolución en la ciudad de La Paz, 1927-1946
}

\author{
Ivanna Margarucci \\ UBA \\ ivannita77@hotmail.com
}

\section{Introducción}

El movimiento anarquista tuvo un gran desarrollo durante la primera mitad del siglo XX en Bolivia. Parte de éste se debió al activismo de las mujeres nucleadas en la Federación Obrera Femenina (FOF) de La $\mathrm{Paz}$, sobre cuya experiencia organizativa y de lucha nos centraremos en este artículo.

Tradicionalmente, estos temas fueron trabajados por la historiografia del movimiento obrero boliviano de forma parcial e incompleta (Lora, 1969-1970), incurriendo en ocasiones en deliberadas distorsiones motivadas por la afinidad político-ideológica de los autores hacia tendencias rivales del anarquismo. Recién en la década de 1980 esta situación comenzó a ser revertida por una serie de investigaciones, a cuya cabeza estuvo el Taller de Historia Oral Andina (Lehm y Rivera Cusicanqui, 1988), que, junto a otros trabajos elaborados a partir del 2000 (Rodríguez García, 2010a), han logrado reconstruir, aun de forma inconclusa, la historia del anarquismo en Bolivia. Fue también en los 80 cuando se desarrollaron los primeros estudios específicos sobre las cholas anarquistas (Dibbits et al., 1989; Wadsworth y Dibbits, 1989), realizando las investigadoras del Taller de Historia y Participación de la Mujer (Tahipamu) entrevistas individuales y colectivas a las longevas libertarias, un valioso material luego utilizado para analizar la trayectoria de la FOF y sus sindicatos.

Estas entrevistas, así como una serie de documentos escritos -publicaciones de origen boliviano (manifiestos y prensa anarquista y comercial) y prensa anarquista de otros puntos del continente relativa al movimiento libertario en Bolivia- constituyen el repertorio de fuentes usadas en el presente trabajo.

En esos documentos aparecen mencionadas por igual, las ideas y las acciones de la FOF, de sus sindicatos y de sus miembros, de lo cual 
surge la primera precaución metodológica que tendremos en cuenta: la estrecha relación existente entre el discurso y la praxis, lo cual nos lleva a plantear la necesidad de analizar a estos elementos como un conjunto inescindible.

La pretensión de dar cuenta del fenómeno en su real complejidad, no se agota en lo anterior.

Últimamente, los estudios latinoamericanos y de la región andina han propuesto la utilidad de aproximarse a los sujetos sociales a partir de la articulación de dos categorías -clase-etnia (Melgar Bao, 1990) o etniagénero (Stephenson, 1994 y 1997)- o de todas ellas (Rivera Cusicanqui, 2010), sin acordar, no obstante, en "la" contradicción fundamental de la sociedad abordada y "la" categoría central de análisis.

En esa dirección, las fuentes, ${ }^{1}$ así como algunos aspectos que plantearemos sobre la FOF, nos remiten al uso articulado de las categorías de "clase, etnia y género", al constituir estos los principales clivajes del caso que nos ocupa. Asimismo, la explotación económica, la discriminación étnica y la dominación patriarcal fueron tres modalidades "opresivas" que convergieron en sus miembros, teniendo la primera de ellas un rol estructurante en la intersección e interacción de esas múltiples identidades. El nombre y el carácter dados a su federación así como sus manifiestos enfatizan la identidad obrera y proletaria del sujeto, destacándola por sobre su condición étnica y genérica (aun cuando las tres aparecen relacionadas).

Así, sostendremos como hipótesis que la triple condición categórica y opresiva (clasista, étnica y de género) que se amalgamó en las mujeres de la FOF posibilitó el fuerte arraigo y la orientación de su lucha a partir de las ideas del anarquismo, al constituir un grupo social "oprimido" tal como fuera concebido por la teoría anarquista (Margarucci, 2010). ${ }^{2}$

1. La Antorcha (10 de julio de 1929) se refiere a sus miembros como "las [...] mujeres proletarias, "cholas", educadas en la lección única y sin posibles alegrias del traginante dolor de su raza castigada y ofendida".

2. Para Bakunin la "tríada explotadora y opresora", integrada por el Estado, la Iglesia y el capital, ejercía la explotación económica, pero también la dominación y opresión política, cultural y moral. El obrero explotado era al mismo tiempo un oprimido en todos esos aspectos. De aquí se derivaban dos cuestiones. Primero, la consideración de un sujeto social amplio -integrado por los trabajadores del campo, de las fábricas (proletarios) y de las ciudades (artesanos) (Bakunin, 1978: 267)- y flexible, ya que el mismo podía (debía) variar en función del medio social particular y concreto de inserción del anarquismo. El carácter integral de la dominación y, por ende, la amplitud y flexibilidad del oprimido lo eran con un sentido netamente clasista. Segundo, la militancia planteada por los ácratas, así como la revolución imaginada por ellos, era total: la puesta en acto de la liberación de las distintas cadenas que ataban al pueblo. 


\section{La tensión entre el cambio y la continuidad}

No es posible pensar la bonanza minera que vivió Bolivia a fines del siglo XIX con el esquema de la economía del enclave. La monoproducción de estaño destinada a los centros del mercado mundial produjo importantes cambios a nivel interno: el mejoramiento de la infraestructura $\mathrm{y}$, principalmente, el crecimiento en tamaño y población de ciudades como La Paz, Oruro y Cochabamba. Crecimiento que se tradujo en el desarrollo, tímido, de algunas industrias urbanas, no obstante lo cual, el sector secundario continuó estando dominando por la pequeña producción artesanal. Esta, junto al comercio minorista de productos primarios y otras actividades informales, aumentaron proporcionalmente a la expansión de la demanda urbana (Margarucci, 2009).

Sin embargo, tampoco debemos exagerar el carácter novedoso de la estructura económica, social y política de Bolivia durante la primera mitad del siglo XX. Ya que, desde finales del XIX, el país atravesó un proceso de modernización contradictoria, en virtud del cual su formación económico-social combinó ciertos rasgos capitalistas con otros precapitalistas, subordinados y funcionalizados por los primeros.

Así, aquellas actividades mineras y urbanas, además de las rurales, ${ }^{3}$ hundian sus raíces en la colonia. Del mismo modo, el sistema social y jurídico-político boliviano se caracterizó por la jerarquía, el racismo y la exclusión. Barragán (2004 y 2005) señala que, pese a la impronta liberal de la joven república, persistió en la Constitución de 1826 y la legislación civil y penal la noción medieval de "patria potestad": "El poder investido en el patriarca", que establecía la autoridad del señor sobre sus siervos, del rey sobre sus súbditos, del padre sobre sus hijos y del esposo sobre su mujer. De origen colonial, el principio reapareció en la era republicana como forma de refuncionalizar los antiguos clivajes sociales, al ser capaz de articular "las relaciones jerárquicas de género, edad, etnia y clase y legitimar el uso de la violencia" (Barragán, 2005: 31 ) en las esferas pública y privada. La centralidad del concepto para el andamiaje sociopolítico y jurídico de Bolivia fue tal, que recién logró ser deconstruido, parcialmente, tras la revolución de 1952.

La "clase-estamento" y la etnia dieron forma, articuladamente, a la piramidal estructura social boliviana. La clase dominante, constituida por una oligarquía minera y latifundista (apodada "La Rosca"), criolla, blanca o "blanqueada", ocupaba la cúspide. La base la integró un in-

3. Bolivia fue durante la primera mitad del siglo XX un país predominantemente rural. Las actividades agrarias -como en la colonia- se desarrollaban en extensos latifundios, constituidos a partir del avance de la oligarquía sobre las tierras y recursos de las comunidades indígenas y explotados con su trabajo no remunerado, mediante instituciones también coloniales como el colonato, pongueaje y mitanaje. 
cipiente proletariado (minero y, de a poco, industrial) junto a la masa campesina mayoritaria, de raices indígenas aymaras y quechuas. De entre las grietas de esos estratos, emergió el mundo mestizo o cholo de los artesanos y de las comerciantes.

Algunos aspectos de este ordenamiento social colonial fueron reajustados a las necesidades del naciente capitalismo. Por ejemplo, el fuerte disciplinamiento en el espacio público y en la esfera privada (de la familia, la moral, la sexualidad, la higiene y la alimentación), promovido por la elite en el pasaje de los siglos XIX a XX a fin de convertir a los díscolos sectores subalternos en trabajadores dóciles (Larson, 2007).

En la misma línea, la superestructura estatal (liberal y republicana en teoría, conservadora en la práctica) se distinguió por la restricción de la participación electoral y política. Hasta 1952, la no subordinación y la alfabetización (asociada a la inteligencia) definieron al ciudadano: todo hombre mayor a 21 años o casado, alfabetizado y con profesión distinta a la de sirviente doméstico. Menores, mujeres e indígenas bolivianos, poseían ciertos derechos civiles, pero no así derechos políticos habilitantes para votar o ser votados. Esta restricción legal complementada con el fraude y el clientelismo garantizaron el monopolio del Estado a la oligarquía.

\section{Mujer(es) en la Bolivia prerrevolucionaria}

La verticalidad de las relaciones de género fue un elemento central en la articulación entre e intra los distintos grupos sociales bolivianos, por lo menos de acuerdo a la lógica jerárquica de la patria potestad -vigente, como dijimos, hasta después de la revolución de 1952-. Por ella, la mujer estaba sujeta durante toda su vida a la autoridad de un hombre: su padre primero y su marido después. Así como recibía su protección, debía al pater familias la más absoluta obediencia, lo que iba desde comportarse de forma respetuosa hasta requerir permiso para, por ejemplo, dejar el hogar o vender y comprar propiedades. La desobediencia era pasible de ser punida con la violencia verbal y física ("pequeños castigos" habilitados por ley) y con sanciones judiciales. La sujeción femenina, junto a su incapacidad intelectual innata, determinaron la proscripción de su participación electoral, política y judicial. Patria potestad mediante, se levantó una "frontera esencial o natural entre el espacio público oficial donde regía el hombre de los sectores dominantes [...] y la esfera privada o doméstica" (Stephenson, 1994: 17) reservada a las mujeres.

Sin embargo, no todas las mujeres eran iguales: ni para la ley, ni para la sociedad y el discurso hegemónico en ella.

La anterior legislación planteaba una distinción de acuerdo a la 
honradez asignada socialmente (entre la mujer honrada, de "reputación desconocida" y de "mala reputación" -la "mujer pública" o prostituta-) y establecía derechos, obligaciones y sanciones diferenciales para cada una. De ésta, se derivaba una segunda diferenciación relativa al estatus legal y derecho al apellido y a la herencia paterna de los hijos de esas "clases" de mujeres, los cuales podian ser "legitimos" (reconocidos, nacidos en matrimonio), "naturales" (reconocidos, nacidos en condiciones en que sus padres podian haberse casado libremente) o "ilegítimos" (no reconocidos, nacidos en el marco de relaciones pre o extramaritales). Todo esto, con una consecuencia fundamental: aquella mujer que tuviera hermanos varones, fuera hija natural o ilegitima o madre de hijos de esa condición, no podía recibir herencia, lo cual complicó y condenó económicamente al género femenino en su conjunto.

Estas distinciones y prescripciones legales se sustentaron en lo que Stephenson (1994 y 1997) define como la "ideologia dominante de la feminidad", la cual, además de gobernar las pautas de comportamiento del género, estableció los parámetros (funcionales, sociales y étnicos) para determinar la propia pertenencia a él de algunos grupos en detrimento de otros. ¿Quién era mujer? La "señora", mujer-madre de clase alta, confinada al ámbito doméstico y definida por sus funciones corporales (pero distanciada de los placeres de la carne) y morales (el afecto y el sentimiento). La "chola", trabajadora urbana vestida de pollera, representaba una categoría límite y peligrosa de la feminidad: no era "señora" aunque sí "mujer", laboral y sexualmente activa. Finalmente, la "no-mujer" seria "la indígena", definida a partir de un epíteto anclado, no en la biología o el género, sino en la raza.

Sin embargo, no fueron las originarias las más afectadas por el orden erigido en base a la patria potestad y reajustado por el disciplinamiento. "Fueron precisamente las mujeres de las clases populares urbanas y de las clases medias las que más sufrieron [sus] consecuencias" (Barragán: 2004: 123). Fueron también ellas las que padecieron la nueva legislación que regulaba el acceso al espacio público; las que vieron sus cuerpos regimentados por los modelos médicos y biológicos y normalizados con la educación; y las que fueron "hambreadas" con fines domesticadores (Stephenson, 1997: 171). Y no por casualidad, fueron aquellas, las cholas, las que de entre esa diversidad de lo femenino, lograron construirse de forma más autónoma.

\section{Mercados y cocinas para preparar la revolución}

En verdad, la autonomía de las cholas fue la resultante de un proceso de construcción: comenzó siendo económica, para ser más tarde política.

Tanto el comercio minorista de productos primarios en el único 
mercado cubierto y calles de La Paz, así como otras actividades informales (el servicio doméstico culinario, por ejemplo) fue desde la colonia dominio casi exclusivo de mujeres mestizas e indígenas. Estos rubros se vieron incrementados, primero a fines de siglo con la expansión de la demanda urbana y después durante la Guerra del Chaco (1932-1935) con el envío de los hombres al frente y la conversión de las mujeres en sostén de hogar.

De este modo, los mercados y las cocinas de las casas de la oligarquía de La Paz se constituyeron como espacios primordialmente femeninos, integrados por quienes alli trabajaban y por quienes recurrian a ellos para satisfacer sus necesidades de bienes y servicios: las mujeres compradoras y las "señoras" empleadoras del servicio.

En esos espacios, las cholas tuvieron un rol estratégico: económico, vinculado al abastecimiento de bienes de primera necesidad a precios populares y la provisión de servicios tan suntuosos como necesarios (la cocina) para la élite; y social, merced a la función de "bisagra" que por su condición mestiza desempeñaban entre la cúspide y la base de la sociedad boliviana (Rodriguez García, 2010b: 13).

Las cholas, con esas profesiones en el mercado informal de trabajo, intentaban escapar de la pobreza y subordinación social que el orden político y jurídico intentaba imponerles. Un objetivo que consiguieron parcialmente. La "recoveras" o "qhateras" no eran más que vendedoras cuentapropistas de escasos bienes, equivalentes a un "miserable capital de 50, 100 o hasta 100 [bolivianos] máximo al dia, que por un milagro gana[n] para subsanar las necesidades de su hogar y el sostén de sus hijos". Las culinarias, por su parte, las "que soportan más, las insolencias de [...] la alta sociedad [...] que por el hecho de pagar un miserable salario, creen que la empleada está en la obligación de permanecer junto a la cocina todo el día y toda la noche, como una esclava" (Manifiesto de la FOF, septiembre 1946). Así pues, la relevancia del lugar ocupado contrasta con la situación económica y social de la gran mayoría de ellas. Esta situación fue la que las catapultó hacia la construcción de su autonomía política.

\section{Praxis y discurso de las "agitadoras de buen gusto" y las "polleras libertarias"}

"En la ciudad de La Paz, a los 29 días del mes de abril de 1927, con la suficiente concurrencia de varias delegadas de los diferentes mercados, se acordó formar una Federación Obrera Femenina, con fines de protección mutua y solidaridad, cooperación y beneficencia" (Lora, 1970: 72). La FOF o el Sindicato Femenino de Oficios Varios (SFOV) -nombre que durante este primer período utilizó indistintamente- nacía así, con 
una finalidad más cercana a la de las sociedades de socorros mutuos, dominantes en el sindicalismo boliviano hasta la primera década del siglo XX, que a la combativa agrupación en la que más tarde se convertiría. Un episodio sin parangón, "contrastante con la situación de los demás países" de América Latina, dirá la prensa anarquista argentina (La Antorcha, 4 de marzo de 1930). Aquejaban a estas mujeres, vendedoras de frutas y floristas algunas cuestiones puntuales que buscaban resolver con la organización: la construcción de mercados seccionales y el fin de una oprobiosa institución colonial, el "maestro mayorazgo" (Dibbits et al., 1989: 15). ${ }^{4}$

Las reyertas entre socialistas y anarquistas por orientar a las cholas agremiadas colmaron sus primeras asambleas (Lora, 1970: 72-74). Precisamente en este momento toda una tradición de convivencia entre fuerzas de ese signo (plasmada en la Federación Obrera Internacional [1912] y en la primera Federación Obrera del Trabajo [1918], ambas de La Paz) era puesta en jaque, debido a la mayor influencia desarrollada por el socialismo y, principalmente, el anarquismo en el mundo obrero-artesanal.

De mayor peso que las palabras habrian sido los vínculos familiares y sentimentales mantenidos por las cholas con algunos artesanos y activistas libertarios (La Antorcha, 10 de julio de 1929), en principio, responsables por la adhesión de la FOF a la Federación Obrera Local (FOL) (fundada en agosto de 1927, a partir de la reunión de cuatro sindicatos libertarios masculinos) y su progresiva inclinación hacia el anarquismo. Una ideología devenida movimiento que, por lo menos hasta 1932, tuvo un carácter masivo en el medio urbano y un influjo para nada desdeñable en el agro entre los indigenas.

Si bien la autonomía de las mujeres con respecto a la FOL se veía limitada, el crecimiento del gremio así como las acciones que emprendió revirtieron esa situación inicial, volviéndose más horizontal su relacionamiento. Entre 1928 y 1930, el sindicato se convirtió en uno verdadero de "oficios varios", al extender su campo de acción y nuclear además a culinarias, lavanderas y lecheras. ${ }^{5} \mathrm{El}$ mismo, de a poco, intervino en diversas clases de actividades.

4. Las "maestras mayores" o "cholas potentadas" eran la autoridad máxima de los mercados. Su función era cuidar los precios y el orden, regular el comportamiento de las recoveras y hacer las veces de intermediarias entre estas y las autoridades estatales (comisarios, intendentes y alcaldes). Los abusos y perjuicios hacia las qhateras y la connivencia con los funcionarios, buscando favorecer la situación propia y de ellos, fue moneda corriente, por lo menos, hasta la aparición de los sindicatos femeninos (Rodríguez García, 2010a: 189).

5. No hay datos concluyentes acerca del tamaño de la primera FOF. La bibliografia sólo menciona los nombres de unas pocas militantes, lo que haría pensar que se trató de 
En mayo de 1929, participó en la Primera Convención Nacional de Mujeres organizada por el Ateneo Femenino. ${ }^{6}$ Alli presentaron una ponencia titulada "La ignorancia es la madre de la esclavitud", en la que denunciaban la particular situación de la mujer proletaria. Su lectura fue interrumpida por el debate que la irreverente crítica causó entre las "damas linajudas y seudo-aristocráticas". Este hecho motivó el abandono del congreso por parte de las sindicalistas (La Antorcha, 10 de julio de 1929). Días después, realizaron una manifestación apoyada por la FOL, en donde expresaron en discursos en aymara su descontento contra el elitismo de la Convención (Lehm y Rivera Cusicanqui, 1988: 37; Rodríguez García, 2010a: 74).

El mes siguiente, Luis Cusicanqui, figura central del anarquismo boliviano, fue detenido. Por segunda vez en un lustro iba a ser confinado a lejanas regiones, debido a la redacción de un manifiesto donde denunciaba las injusticias padecidas por los indígenas y los convocaba a la lucha (Margarucci, 2014). Inmediatamente, la FOL y la FOF realizaron una manifestación pública frente al Palacio de Gobierno, exigiendo su no confinamiento y libertad. La misma fue salvajemente reprimida. La policía dispersó la concentración -compuesta en su mayoría por las mujeres del SFOV- a "caballazos y a sablazos", deteniendo a "los manifestantes, sin distinción de sexo [...] La forma como trasladaron a los detenidos [...] fue por demás cruel [...] se los conducía de los cabellos propinándoles golpes por la espalda. Fue también conducida presa una mujer que llevaba una criatura cargada a la espalda [...] arrebatada por los carabineros" (La Protesta, 7 de julio de 1929). ¿El saldo? "Un centenar de compañeras afiliadas al sindicato femenino" presas y muchas más "convalecientes en el hospital" (La Continental Obrera, septiembre de 1929).

Así, desde el comienzo, las cholas anarquistas movilizadas por rei-

un grupo relativamente pequeño. Según La Continental Obrera (septiembre de 1929) habria superado la centena de militantes. No obstante, ello no fue en desmedro de su gran capacidad de movilización y efectividad para una fecha tan temprana como 1930: "Contra este sistema [el carnet de identidad pago], las mujeres de La Paz, orientadas por el sindicato femenino, opusieron gran resistencia. Uno de los actos [...] fue la grandiosa manifestación que congregó más de 10.000 mujeres, que hicieron el fracasar el intento del tirano Siles" (La Antorcha, 4 de marzo de 1930).

6. Las cholas no fueron las únicas que se organizaron en las primeras décadas del siglo XX, siendo esta "una coyuntura de suma importancia en la historia de las organizaciones de mujeres en Bolivia". Las "señoras", partiendo de la ideología de la feminidad (no negándola), formaron grupos culturales y revistas femeninas (el Ateneo Femenino, la Sociedad Femenina Pro-Cultura, la Asociación Cristiana y la Legión Femenina de Educación Popular) para dar los primeros pasos en la "emancipación femenina": derecho al voto, educación y trabajo fuera de casa (Stephenson, 1994: 18-19; Dibbits et al., 1989: 75). 
vindicaciones corporativas y ajenas experimentaron en carne propia los escarmientos con que el Estado contestaba la rebeldía plebeya. Continuarian padeciéndolos, sin importar sus consecuencias, durante las décadas siguientes.

La represión estatal -iniciada bajo la presidencia de Siles (1926-1930) y continuada por sus sucesores, Blanco Galindo (1930-1931) y Salamanca (1931-1934)- logró a corto plazo su objetivo: las agrupaciones anarquistas en auge debieron pasar a la clandestinidad (como la FOL) o interrumpir sus actividades (como la FOF), sufriendo descalabros organizativos y la virtual paralización de sus actividades. Sin embargo, el Estado boliviano no logró desarticular definitivamente al movimiento. De hecho, el caso de estas aguerridas mujeres demuestra que el contexto reaccionario, enmascarado tras la Guerra del Chaco, no hizo más que potenciar su organización y su lucha.

El fin del conflicto bélico abrió un nuevo capítulo en la historia del movimiento anarquista boliviano. Una parte importante del mismo lo escribieron las cholas, quienes en 1940 refundaron la FOF, a partir de la reunión de los sindicatos femeninos libertarios organizados en los años precedentes: el Sindicato de Culinarias (SC) en 1935, la Unión Femenina de Floristas (UFF) en 1936, los sindicatos de recoveras (entre 1938 y $1940)^{7}$ y el Sindicato de Viajeras al Altiplano (SVA) ${ }^{8}$ en 1940 . Durante más de una década, la importante experiencia de la $\mathrm{FOF}^{9}$ constituiría el puntal de la FOL.

El contexto de crisis política y económica de la inmediata posguerra y su forma de resolución explican tanto la retracción de los sindicatos masculinos como la hegemonía conquistada por las mujeres dentro del movimiento anarquista.

Los cambios introducidos en la matriz liberal del Estado boliviano con la experiencia del Socialismo Militar (1936-1939) y el impacto que estos tuvieron en la restructuración del movimiento obrero, a partir de la promoción de un sindicalismo de cuño estatal (creación del Ministerio de Trabajo dirigido por el obrero gráfico Waldo Álvarez y "decreto de sindicalización obligatoria" mediante) y la consecuente ilegalización del

7. "Sindicatos específicos por gremio, como el de Trabajadoras en Vianda (Comideras), Fruteras Minoristas, Lecheras y Comerciantes Minoristas; por otro lado, con la creación de nuevos mercados se organizaron sindicatos en cada uno de estos [...] como los del Mercado Camacho y Sopocachi" (Dibbits et al., 1989: 21).

8. Bajo este simpático nombre se reunieron mujeres que compraban y vendian productos en la frontera entre Bolivia y Perú (léase contrabandistas a pequeña escala).

9. Durante la década del 40 llegó a reunir entre doce y trece sindicatos de mujeres (Petronila Infantes, en Wadsworth y Dibbits, 1989: 130; La Calle, 8 de agosto de 1945), manteniendo asimismo el masivo apoyo popular del período precedente (" 5 mil mujeres del pueblo pidieron ayuda al Parlamento", en Inti, 13 de diciembre de 1940). 
anarquismo y comunismo, tuvieron consecuencias irreversibles en el devenir de la FOL. Sus sindicatos se debatieron entre el pragmatismo y la participación de las iniciativas estatales y las nuevas estructuras sindicales (el "Primer" Congreso Obrero de 1936 y su "hija": la Confederación Sindical de Trabajadores de Bolivia) y el principismo y la radicalización sintetizada en la defensa de la autonomía, del apoliticismo y del antiestatismo. Al divisionismo, le siguió la deserción de algunos gremios y "las idas y vueltas" entre ambas matrices sindicales de otros (Margarucci, 2009 y 2014).

Lehm y Rivera Cusicanqui (1988: 69) señalan dos causas por las que este contexto fue favorable para el reposicionamiento de las mujeres y sus sindicatos. En primer lugar, la crisis inflacionaria y el desabastecimiento de posguerra las encontraron con una sólida posición en el mercado de trabajo, a partir de la cual se autoorganizaron y organizaron a otras. En segundo lugar, el carácter cotidiano de sus demandas las habrian colocado al margen de los debates y divisiones doctrinarias, desarrolladas si entre los hombres.

En verdad, la última afirmación de las autoras debe ser matizada, puesto que las cholas sí se involucraron en las discusiones de posguerra, manteniendo una postura anarquista firme y consecuente, intransigente respecto del "desviacionismo" manifestado por algunos militantes y sindicatos masculinos.

Las mujeres como la Rosa [Rodríguez de Calderón, culinaria, fundadora del SC], la Cata [Catalina Mendoza, florista, fundadora de la UFF], la Peta [Petronila Infantes, culinaria, "dirigente" del SC] se han mantenido como una raíz... enraizada en la tierra, que no han podido torcer jamás. (Lisandro Rodas, en Lehm y Rivera Cusicanqui, 1988: 158)

Esta radicalización no les impidió "aprovechar", con cautela, las nuevas posibilidades ofrecidas por un Estado dispuesto a hacer algo más por el movimiento obrero que tan sólo reprimirlo. En esa clave debe ser leída la postura del SC, favorable a participar en el Congreso Obrero de 1936, en tanto instancia pertinente donde hacer oír sus demandas gremiales, o lo que señala Alicia Infantes (hija de Petronila) sobre el aumento de la agremiación, promovida desde las esferas estatales durante el Socialismo Militar (Wadsworth y Dibbits, 1989: 79). De igual modo, el antiestatismo característico del discurso y de la praxis de las cholas de la FOF no fue contrario, sino que se articuló -de forma contradictoria- con el reclamo por y el apoyo a determinadas leyes emanadas del mismo Estado con el que querian acabar. 


\section{Demandas de clase y dignidad del trabajo femenino}

Como vimos, estas mujeres trabajadoras estuvieron ocupadas en la provisión de algunos servicios: el comercio minorista por cuenta propia en la vía pública (recoveras o qhateras, floristas, contrabandistas) o el trabajo doméstico (culinarias). ¿De qué formas expresaron su identidad clasista, constituyente de la contradicción principal a partir de la cual estructuraron su lucha?

En primer lugar, a partir de las demandas concretas, que como en el periodo anterior, motivaron en este la fundación de sus sindicatos y fueron el eje de sus reivindicaciones.

En algunos casos, no obstante, el carácter económico de las mismas (si a éste se lo equipara tan sólo con la dimensión salarial) se nos pierde de vista. En 1935, el SC se constituyó tras la prohibición municipal que impedía a las cholas cocineras utilizar el transporte público, causada por la queja de las "señoras" de "que al subir [...] les rasgábamos las medias y les incomodábamos con las canastas" (Petronila Infantes, en Lehm y Rivera Cusicanqui, 1988: 173), lo cual no era absolutamente cierto, ya que ni siquiera compartían los vagones de los tranvias, divididos en primera y segunda clase (El Diario, 31 de julio de 1935). Del mismo modo, la UFF se fundó al año siguiente y otros sindicatos de qhateras lo hicieron entre 1938 y 1940, para reclamar a las autoridades municipales por la construcción de nuevos mercados. Finalmente, en 1940 , las integrantes del SVA se agremiaron para acabar con los abusos de las autoridades aduaneras (Margarucci, 2009 y 2010).

A pesar de la diversidad de razones que motivaron la organización de las cholas, su "conciencia clasista" las llevó a hacerlo en sindicatos y federaciones obreras, y no en otro tipo de estructuras desprovistas de esa connotación (como las damas de la oligarquía). Así lo afirmaban las propias protagonistas: "Nosotras hemos dicho que [...] no vamos a ser Sociedad Mutual, vamos a ser Sindicato" (Petronila Infantes, en Wadsworth y Dibbits, 1989: 71). La necesidad planteada de "evolucionar" del mutualismo al sindicalismo representa además un salto ideológico importante respecto de los móviles ligados a la fundación del SFOV allá por 1927.

Asimismo, esos sindicatos sostuvieron una gran cantidad de demandas y reivindicaciones que apuntaban a mejorar la situación material y las condiciones de trabajo. Demandas que beneficiaban a cada gremio, como en el caso de las culinarias -que reclamaron por la jornada laboral de ocho horas (conquistada por los trabajadores varones en 1930) e incrementos salariales acordes a la ley (La Calle, 16 de octubre de 1936; Inti, 20 y 23 de marzo de 1941) o contra el encarecimiento del pasaje del tren- o en el de las "viajeras", que aún en la más absoluta informalidad 
pidieron mejores condiciones de trabajo (mejores caminos) iy el pago de una suerte de aguinaldo!. ${ }^{10}$

Pero también fue notable la actuación de las recoveras, que desde ese lugar estratégico protagonizaron en la década del 40 manifestaciones de grandes dimensiones contra el sobreprecio de los artículos de primera necesidad - jllegando a "tomar" el Palacio de Gobierno y entrevistarse dos veces con el propio presidente Peñaranda! (Rodríguez García, 2010a: 186-190)-, hecho que, como explicitaban, afectaba al conjunto del "pueblo consumidor" del que se sabian parte integrante (Inti, 20 de marzo de 1941).

El interlocutor principal de las cholas, como leitmotiv de fundación de los gremios y como sujeto de reclamo en la articulación de sus demandas, fue el Estado en sus distintos niveles. Emerge aquí el "otro" frente al cual constituyeron el "nosotras".

Un Estado que en pocas ocasiones intervino en su favor, otorgando a los gremios lo que reclamaban (el uso y el precio del tren, la construcción de mercados). Pero que en la mayoria de ellas fue prescindente, desconociendo las demandas y desoyendo las soluciones de las sindicalistas (por ejemplo, la falta de la capacidad de los nuevos mercados construidos [Manifiesto de la FOL, 28 de agosto de 1938] o el control de precios de los bienes de primera necesidad).

Una pasividad contrastante con el rol activo, reaccionario en esencia, que desplegó regularmente el Estado hacia estas mujeres "del pueblo". Dicha actitud se cristalizó en un amplio repertorio, un "continuum" represivo, que fue desde la violencia más "microfísica" -los abusos diarios en los mercados a manos de la policía o de las maestras mayores-, hasta la represión abierta -violencia, encarcelamiento y muerte- (Manifiesto de la FOL, 28 de agosto de 1938).

Así, una parte importante de su actividad consistió en enfrentar esta diversidad de atropellos estatales. Las conclusiones de la lucha fueron tan concluyentes como insistentes sus denuncias: "Las autoridades encargadas de amparar y de hacer cumplir las leyes, [están] de lado de los "patrones", enemigos de los "obreros"” (El Pueblo, 31 de julio de 1948). El carácter de clase de la maquinaria estatal se revelaba en cada una de sus arbitrariedades y, a partir de esa revelación, las mujeres se posicionaban a un tiempo contra el Estado y contra quienes apañaba: los "patrones", "los señoritos y damitas de alta sociedad [...] los propietarios de las fincas [...] la burguesía urbana [y] los comerciantes intermediarios" (Manifiesto de la FOF, septiembre de 1946).

10. "Ya cuando llegaba la Navidad, les decía [a los aduaneros]: "Mire, dénos un día para que pasemos nuestras cositas, así como aguinaldo". [...] Las autoridades nos concedian. Porque nosotras dábamos entrada al Estado, de las pólizas, de todo lo que se trae, lo que no produce el país" (María Mejía, en Dibbits et al., 1989: 47). 
El padecer su condición de clase como mujeres "proletarias", "obreras", "explotadas" y "humildes" (como las referencia la prensa) parece no haber sido contradictorio con la "prédica dignificadora del trabajo de la mujer" (Lehm y Rivera Cusicanqui, 1988: 70) que manifestaron de diversas maneras. Reivindicando la calidad de su trabajo y su producto, en tanto fruto de la creación artesanal y artística libre (como se advierte en los discursos de las culinarias ${ }^{11}$ y floristas) o exaltando el rol "social" cumplido por sus oficios y reclamos (como plantearon las viajeras y recoveras).

\section{"Bolivia es de cholas..."}

Desde los inicios de la federación, sus integrantes se valieron de la reivindicación de su identidad chola para articular la formulación de esas demandas concretas y emprender luego la lucha: "La mujer de hoy dia, en especial la chola boliviana, conoce sus derechos, por eso reclama con todo el valor y con toda convicción, cara a cara: ¡No más atropellos, no más injusticias!" (El Hombre, 10 de agosto de 1929).

¿Pero qué era ser cholo? ¿Y chola?

Tras la conquista y colonización española del espacio andino, tempranamente, apareció el mestizo: sujeto liminar que, habitando la ciudad colonial y manteniendo lazos (étnicos, sociales y principalmente culturales) con su pasado y comunidad de origen, unía las dos repúblicas -de españoles y de indios- que jurídicamente se querian separadas (Barragán, 1992: 92; Rodríguez García, 2010b: 40-43).

Durante el período republicano, la variabilidad y la imprecisión de los rasgos culturales que definían al cholo masculino contrastaba con aquellos asumidos como parte de la "identidad tácita" de la chola femenina: la pollera de varias capas, larga o corta, con tablas y cintas de colores -tomada de las mujeres españolas durante el siglo XVIII, como forma de distanciamiento de la sociedad indígena-, a lo que se añadía una particular actitud, forma de hablar y de comportarse (Barragán, 1992: 101-108; Rodríguez García, 2010b: 39). Se distinguía además entre ambos el ocultamiento, valoración negativa o aceptación resignada que el cholo hacía de tal identidad y la autoafirmación positiva realizada por la chola.

Antes que una particular condición étnica, ser cholo o chola era y es aún hoy una forma de identificación relativa y fluida.

Como bien señala Rodríguez García (2010b: 49) la sindicalización y

11. Algunas demandas que llevaron al Congreso de 1936 dan la pauta de este "doble discurso", clasista y dignificador: la jornada de ocho horas y el descanso dominical conjuntamente con el reconocimiento del arte culinario como profesión. 
adscripción al anarquismo de las mujeres fue un factor determinante, entre otros, para la emergencia de tal prédica valorativa.

Los sindicatos de la FOF contestaron el "culto del antimestizaje" desarrollado por la "blanca" oligarquía para justificar tanto la dominación y explotación, cuanto la discriminación y los abusos hacia los grupos mestizos (Larson, 2007).

"La gente rica nos ultrajaba mucho a nosotras: siempre nos trataba de india, de chola [...] No podíamos ni entrar al cine, porque decían que somos de pollera [...] Nos acercábamos a una heladería [...] y nos decían que no había servicio para nosotras. Esas ricas no permitian que una niña de gente humilde entre a un colegio particular. Si [...] en las casas, una manejando una taza la rompia, de eso le descontaban”. (Exaltación Miranda, en Wadsworth y Dibbits, 1989: 60)

La ideología dominante, como las mismas cholas, ponía en estrecha relación a la raza y al vestido. Pero además, su pollera constituía el "símbolo hegemónico" de un cuerpo desordenado y contaminado, en alusión a la pretendida falta de higiene y patologías que portaban (Stephenson, 1997: 27). Tales, de hecho, fueron los argumentos para prohibir el uso de los trenes a las culinarias (El Diario, 31 de julio de 1935) o para intentar imponerles un carnet de sanidad, expedido por la Policía de Higiene (encargada también del control médico de las prostitutas).

Este entramado discursivo, articulado con la patria potestad, determinó que los mestizos fueran tenidos por ciudadanos de segunda, "extranjeros en país propio": "Las oradoras [de una movilización de recoveras] hablaron en aymara, quechua y castellano, diciendo: "Qué somos nosotras, chinas o turcas? No somos bolivianas?" (...) ¿Es una vergüenza para la ciudad que vendan en las calles las pobres?" (La Calle, 10 de agosto de 1938).

Si con el paso del tiempo la pollera se convirtió en un elemento definitorio de la identidad chola y en un pilar de la apología xenófoba de la elite, las activistas de la FOF se reapropiaron de ella convirtiéndola en un emblema de sus reivindicaciones de clase, de etnia y de género y en un símbolo de "resistencia y negación a adaptarse completamente a la cultura hegemónica de la nación imaginada por las elites" (Stephenson, 1994: 31) ¿Cómo fue que lo hicieron?

En primer lugar, poniéndole freno a la discriminación y abusos de los hombres y "señoras" de la élite -con quienes se topaban a diario en sus espacios de trabajo-. Ciertamente, el intento de modificar sus arbitrarios malos tratos fue exitoso. Como señala Exaltación Miranda (en Wadsworth y Dibbits, 1989: 60): "Las mismas señoras de ahora 
dicen: "ay, no hay como las empleadas de antes"”, acostumbradas, en comparación a las actuales, al silencio y a la sumisión.

En segundo lugar, la mayoría de sus reclamos fueron en simultáneo demandas por ampliar, por hacer más inclusiva aquella ciudadanía en el derecho y en los hechos restringida (Lehm y Rivera Cusicanqui, 1988: 38). "Siguen odiándonos pero, ¿qué haremos? Yo les digo: "país de cholas es pues éste, no es de extranjeros: si es extranjero, váyase pues usted a su país. Bolivia es de cholas..."” (Natividad Veramendi, en Wadsworth y Dibbits, 1989: 57).

\section{Igualdad de género, derechos familiares y laborales}

Las diferencias entre el cholo y la chola y la importancia de la pollera ilustran cómo la identidad étnica convergió con la de género. Asimismo esta se articuló con la adscripción clasista:

Por el hecho de ser mujer se nos paga menos que al hombre y se nos hace trabajar más [...] La existencia de la mujer oscila en el campo mezquino de su destino, cuyas fronteras se pierden en la negrura de la fatiga y el hambre o en las tinieblas del matrimonio y la prostitución. (Petronila Infantes, citada en Wadsworth y Dibbits, 1989).

Clase y género se "retroalimentaban": a la mujer se la explotaba más que al hombre, lo que la conducía a aceptar infamantes instituciones y prácticas patriarcales en tanto únicas alternativas disponibles.

El "feminismo" plebeyo y cholo tuvo también un correlato organizativo: la federación y sus sindicatos fueron excluyentemente femeninos. Cuando en 1936 los "culinarios y garzones" quisieron ingresar al SC, no fueron admitidos e invitados a "formar otro sindicato aparte" (Petronila Infantes, en Wadsworth y Dibbits, 1989: 74). Sin embargo, el principio federativo, la afinidad ideológica y la complementariedad de la lucha -además de los lazos personales-, fueron la base de una vinculación siempre estrecha con los gremios masculinos de la FOL.

La histórica condición laboral de las cholas constituyó un lugar de privilegio para el desarrollo de la lucha. Al no estar confinadas al ámbito privado de sus hogares, existió desde el vamos una reversión de las pautas tradicionales de división social del espacio y sexual del trabajo y una concomitante autonomía personal y económica, que se proyectó como independencia política. Sin embargo, no estuvieron exentas de otras prácticas opresivas, físicas y simbólicas: la violencia doméstica (legalizada por la patria potestad) o ser responsables por una prole numerosa, vivenciando asi la maternidad como "otra fuente de repre- 
sión" y no como algo deseable y natural (de acuerdo a la ideología de la feminidad) (Stephenson, 1994: 30).

Como el resto de las demandas, sus reivindicaciones femeninas apuntaron a resolver el día a día, teniendo un carácter puntual y práctico.

Así, a partir de una insistente prédica sobre el principio de igualdad entre el hombre y la mujer (que desafiaba la esencia de la patria potestad), las cholas revirtieron y previnieron episodios de maltrato masculino: "Todos tenemos que ser como somos, que no haya discriminación; por eso nos respetábamos el uno al otro, tanto entre compañeros como entre compañeras. Los mismos compañeros con sus esposas bien, ni siquiera se peleaban como en otras partes" (Petronila Infantes, en Wadsworth y Dibbits 1989: 164).

También dirigieron su atención a las reformas legales vinculadas a los derechos de familia. "En 1945 se discutió en el Congreso que el concubinato sea reconocido como matrimonio y ellas apoyaron la medida" (Peredo, s/f: 22). Anteriormente, en 1939, en un gesto de avanzada, las cholas se habian pronunciado por la eliminación de las distinciones legales que existían entre los hijos legítimos y naturales. Todo ello, en abierta oposición a las "damas copetudas" de la oligarquía.

En verdad, la cuestión de la maternidad fue una preocupación central de su accionar sindical. Así en 1941 consiguieron la construcción de guarderias estatales, en donde dejar sus "wawas" mientras ellas trabajaban y ¿por qué no? desarrollaban su militancia (Rodríguez García, 2010a: 190).

\section{Del socialismo libertario al "sincretismo religioso"}

Las demandas concretas, económicas y contra los abusos de las autoridades estatales estuvieron lejos de quedarse en el reformismo; se entroncaron con un planteo revolucionario, anticapitalista y antiestatista. Asimismo, la reivindicación de igualdad ciudadana no apuntó, como otras corrientes del feminismo, a conquistar el voto femenino, calificado por la FOF como "una trampa [...] que al igual que el masculino, tenderá a que los pobres elijamos a los pastores de siempre, gobernantes al fin, que legislarán y ordenarán para conservar las cadenas que hoy nos aplastan" (FOL, 1 de mayo de 1947). ¿Para qué querer votar, si el Estado, y con él las jerarquias sociales, debian ser destruidos? Ahora bien, ¿qué proponían en su reemplazo?

El socialismo libertario [...] es la única doctrina que garantiza la libertad individual y colectiva con la solidaridad y el apoyo mutuo de los productores dentro del sistema federalista, en oposición contra toda doctrina que tenga por base la autoridad 
dictatorial que intente asirse de las riendas del poder Estatal. (Manifiesto de la FOF, septiembre de 1946)

Estas eran las nociones que actuaron como "máximas" para estas mujeres, de funcionamiento de sus organismos gremiales y de la sociedad que aspiraban a construir: la autonomia, la libertad y la solidaridad, apuntaladas por el federalismo, la horizontalidad y la autogestión.

Por su parte, el anarcofeminismo orientó a las cholas en su crítica cotidiana de la opresión masculina, promoviendo en algunas una impugnación profunda y radical de las bases (religiosas y jurídicas) de la dominación patriarcal. Petronila Infantes, por ejemplo, desarrolló un anticlericalismo militante, que le permitió cuestionar: “¿Por qué siempre una se iba a casar? El matrimonio es un negocio para el cura y para el notario" (en Wadsworth y Dibbits, 1989: 140) y optar por el "amor libre": el concubinato.

No obstante, la religión tuvo un gran peso en la sociedad boliviana, sobre todo entre las mujeres. Así se explica el sincretismo religioso de otras miembros de la FOF, gracias al cual integraron de forma tan contradictoria como original la fe y ritos católicos con las conmemoraciones del martirologio anarquista. Natividad Veramendi relata que en las veladas culturales realizadas tras las marchas por el primero de mayo (actividades donde las cholas tuvieron un rol protagónico, organizativo y participativo), ${ }^{12}$ "sabíamos rezar, orar por las almas, la salvación de los compañeros caídos en Chicago [...] que han sufrido junto a nosotros" (en Wadsworth y Dibbits, 1989: 145 y 162).

Se trataba de ciertas prácticas religiosas enraizadas en la cultura colonial, convergentes con un anticlericalismo centrado en la oposición a la Iglesia en cuanto institución aliada a la casta dominante criolla (Rodríguez García, 2010a: 323).

Así, un abismo ideológico, a la vez económico y étnico, separó a las cholas de las distintas expresiones del feminismo boliviano de la primera mitad de siglo. Esta brecha no les impidió participar de los congresos de mujeres, como la Primera Convención de Mujeres de 1929 o la Semana de la Cultura Femenina de 1944; sí construir una base de acuerdos y una agenda común que les permitiera trabajar en conjunto.

12. "Una velada proletaria organizada por la FOL", incluía en 1936 varios números preparados por mujeres, como ser: "Pequeña reseña histórica de la FOL, por la compañera Luz Llanque; una recitación por Lucha Arrueta; un número de charlestón por otra compañera y las intervenciones de tres representantes de sindicatos femeninos" (Dibbits et al., 1989: 74). 


\section{Epílogo}

La activa participación de las mujeres de la FOF en el levantamiento del 21 de julio de 1946, que acabó de manera trágica con la vida y el gobierno del presidente Villarroel (1943-1946), constituyó también el fin de un ciclo para las libertarias bolivianas. Si hasta entonces su lucha se había caracterizado por ser fundamentalmente ofensiva, de aqui en más sus movimientos serian defensivos. Frente a la fuerte represión padecida por el anarquismo durante el sexenio (1946-1952) -a la que ellas denunciaron (FOL, 1 de mayo de 1948) y trataron de combatir, infructuosamente- $y$ las transformaciones del mundo sindical acaecidas con la revolución nacional de 1952, solo pudieron aferrarse e intentar preservar las conquistas sociales y los desarrollos organizativos alcanzados previamente.

En 1955, por su composición, la FOF debió afiliarse a la Confederación Sindical de Trabajadores Gremiales, dependiente de la reciente Central Obrera Boliviana (COB). En ella, sus sindicatos y sus miembros fueron relegados a posiciones marginales, además de ser objeto de una encarnizada persecución ideológica anticomunista. Sindicalistas hombres, sin experiencia e identificados con el movimentismo nacionalista, "políticos", reemplazaron a las cholas qhateras -férreas defensoras aún de los principios del antiestatismo y el apoliticismo- en la ahora menguada lucha de los mercados de La Paz. Así, las viejas luchadoras, una a una, fueron alejándose de la federación. Y con su distanciamiento, los sindicatos quedaron como una cáscara vacía. El golpe de Estado de Barrientos en 1964, con su ofensiva antisindical de 1965, puso un paréntesis a la existencia de la COB y con ello propinó el tiro de gracia que liquidó a la agonizante FOF (Dibbits et al., 1989: 81-86; Rodríguez García, 2010a: 243-266).

\section{Conclusión}

La explotación y opresión sufrida a manos de la oligarquía y de las autoridades estatales por ser trabajadoras y mestizas, del mismo modo que las constricciones sociales, jurídicas y morales padecidas en virtud de ser mujeres, convirtieron a estas cholas en un sujeto potencialmente receptivo y particularmente afin a las ideas libertarias, promoviendo en ellas el desarrollo de una militancia y la emergencia de un contradiscurso caracterizados por su temperamento autoafirmativo, contestatario y de resistencia.

Una experiencia tan importante y trascendente (en términos de la intensa actividad desplegada) como exitosa. Gracias a ella, las mujeres lograron una mejora concreta de su calidad de vida. Los sindicatos las 
educaron en la rebeldia, promoviendo el empoderamiento del que se valieron para autodefenderse y luchar contra cualquier clase de ultraje, proviniera de quien proviniera (la oligarquía, el Estado, su familia, etc.). En esta lucha, pusieron coto a los aspectos más opresivos de la sociedad boliviana, antiguos y modernos: la patria potestad, el disciplinamiento público y privado, la ideología de la feminidad. La elite, acostumbrada a ver a las cholas como vendedoras y sirvientas, ante tal situación, comenzó a debatirse entre el asombro, el respeto, el miedo... Y la resignación de que algo había cambiado.

Esto permite entender el papel hegemónico, de motor y de vanguardia, desempeñado por la FOF dentro de la retraída FOL de posguerra. "Ellas iban por delante y nosotros por detrás" enfatiza Lisandro Rodas (en Lehm y Rivera Cusicanqui, 1988: 159), sugiriendo que, a la inversa que antes, la FOL vio recortada su autonomía por el despliegue de aquella. De hecho, la reorganización de la FOF en 1940 se enmarcó dentro del intento más general por restructurar a la debilitada FOL, en cuyo proceso le cupo un papel protagónico al SC y a Petronila Infantes, elegida como su secretaria de actas cinco años consecutivos (Rodríguez Garcia, 2010a: 164-166).

¿Por qué, entonces, el anarquismo "calzó como anillo al dedo" en las cholas de la FOF?

Esta ideología tenía una mirada amplia e integral respecto de varias cuestiones relacionadas: del carácter de la dominación en el sistema capitalista; del sujeto revolucionario "oprimido" -definición en la que ellas cabian-; de las características del activismo libertario (tal como lo desarrollaron, orientado en múltiples direcciones a partir de diferentes actividades) y de la futura revolución social.

Así, la inclinación hacia el anarquismo de las cholas paceñas no tuvo que ver ni exclusiva, ni principalmente, con los lazos afectivos o familiares mantenidos con los varones de la FOL, sino con su particular situación, objetiva y subjetiva, y cómo esta se "ajustó" a dicho corpus doctrinario, en cuanto forma apropiada, coherente y eficaz de resolverla. No obstante, este no se mantuvo "intacto", sino que algunas ideas, al hacerse carne, al ser asimiladas y llevadas a la práctica, fueron adaptadas a la realidad en la que se manifestaron y acabaron por ser resignificadas por ellas, las polleras libertarias.

\section{Bibliografia}

Bakunin, Mijail (1978), "Tres conferencias dadas a los obreros del Valle de Saint-Imier" [1871], en La revolución social en Francia, Madrid: Júcar, pp. 235-271.

Barragán, Rosanna (1992), "Entre polleras, lliqllas y ñañacas. Los mestizos 
y la emergencia de la tercera república", en Silvia Arze y Laura Escobari (comps.), Etnicidad, economía y simbolismo en los Andes, La Paz: HisbolIfea, pp. 86-123.

- (2004), "Dónde están las mujeres. Legislación y prácticas legales en Bolivia en el siglo XIX", en Norma Fuller (ed.), Jerarquías en jaque: estudios de género en el área andina, Lima: Red para el Desarrollo de las Ciencias Sociales en el Perú-CLACSO, pp. 105-142.

- (2005), "Absent Equality: Infamy, Patria Potestad, Legitimized Violence and its Continuities in Twentieht Century, Bolivia", en Willem Assies, Marco Calderón y Ton Salman (eds.), Citizenship, Political Cultures and State Transformation in Latin America, Amsterdam: Dutch University Press, pp. 31-46.

Dibbits, Ineke, Elizabeth Peredo, Ruth Volgger y Cecilia Wadsworth (1989), Polleras libertarias. Federación Obrera Femenina (1927-1965), La Paz: Tahipamu/Hisbol.

Larson, Brooke (2007), "Indios redimidos, cholos barbarizados: la creación de la modernidad neocolonial en la Bolivia liberal (1900-1910)", en Cristóbal Aljovin y Nils Jacobsen (ed.), Cultura politica en los Andes (1750-1950), Lima: Ifea-UNMSM, pp. 347-373.

Lehm, Zulema y Silvia Rivera Cusicanqui (1988), Los artesanos libertarios y la ética del trabajo, La Paz: Taller de Historia Oral Andina.

Lora, Guillermo (1970), Historia del movimiento obrero boliviano, tomo I y II, La Paz: Los Amigos del Libro.

Margarucci, Ivanna (2009), "La experiencia anarquista en el movimiento obrero boliviano", Deconstruir, ${ }^{\circ}$ 1, Buenos Aires, pp. 38-45.

- (2010), "De cholas, artesanos e indigenas: las ideas anarquistas en Bolivia", Ni Calco Ni Copia. Revista del Taller de Problemas de América Latina, $\mathrm{n}^{\circ}$ 3, pp. 141-162.

- (2014), "De la trayectoria individual a la historia social. Luis Cusicanqui Durán y la experiencia del anarquismo boliviano durante las décadas de 1920 y 1940", ponencia en las IV Jornadas Internacionais de Problemas Latinoamericanos, Foz do Iguaçu, Brasil, 27-29 de noviembre.

Melgar Bao, Ricardo (1990), El movimiento obrero latinoamericano I. Historia de una clase subalterna, México: Alianza Editorial Mexicana.

Peredo, Elizabeth (s/f), La Unión Sindical Femenina de Floristas (Historia del primer sindicato de floristas en la ciudad de La Paz), La Paz: Fundación Solón.

Rivera Cusicanqui, Silvia (2010), Violencias (re)encubiertas en Bolivia, La Paz: La Mirada Salvaje-Piedra Rota.

Rodríguez García, Huáscar (2010a), La choledad antiestatal. El anarcosindicalismo en el movimiento obrero boliviano (1912-1965), Buenos Aires: Libros de Anarres.

- (2010b), "Género, mestizaje y estereotipos culturales. El caso de las cholas bolivianas", Maguaré, n 24, pp. 37-67. 
Stephenson, Marcia (1994), "Hunger as discipline in La Paz, Bolivia 19001952", Dispositio, vol. 19, n 46, pp. 165-178.

- (1997), "Faldas y polleras: las ideologías de la feminidad y la conquista de nuevos espacios públicos en Bolivia (1920-1950)", Chasqui, vol. 26, $\mathrm{n}^{\mathrm{o}} 1$, pp. 17-33.

Wadsworth, Ana Cecilia e Ineke Dibbits (1989), Agitadoras de buen gusto. Historia del Sindicato de Culinarias. 1935-1958, La Paz: Tahipamu/Hisbol.

$* * *$

Titulo: Cooking the revolution in La Paz city, 1927-1946

Resumen: En el presente artículo nos proponemos abordar la experiencia de la Federación Obrera Femenina (FOF) de La Paz, Bolivia, entre 1927 y 1946. Analizaremos la forma en que las "cholas" comerciantes y cocineras, definidas y "oprimidas" por la clase, la etnia y el género, articularon su lucha en esos tres frentes con el marco político e ideológico provisto por el anarquismo.

Palabras clave: Anarquismo - Feminismo - Bolivia - Cholas

Abstract: In this article we aim to address the experience of the Federacion Obrera Femenina (FOF) of La Paz, Bolivia, between 1927 and 1946. We will analyze how the "cholas" merchants and cooks, defined and "oppressed" by the class, ethnicity and gender, articulated their struggle in these three fronts with the political and ideological framework provided by the anarchism.

Keywords: Anarchism - Feminism - Bolivia - Cholas

Recepción: 31 de mayo de 2015. Aprobación: 11 de julio de 2015 